Article

\title{
Using a Coupled Human-Natural System to Assess the Vulnerability of the Karst Landform Region in China
}

\section{Xiang He ${ }^{1,2,3}$, Zhenshan Lin ${ }^{1,3, *}$ and Kangning Xiong ${ }^{4}$}

1 College of Geographical Science, Nanjing Normal University, No.1 Wenyuan road, Qixia district, Nanjing 210023, China; E-Mail: 141301005@stu.njnu.edu.cn

2 College of Tourism, Kaili University, No. 3 Kaiyuan Avenue, Develop district, Kaili 556011, China

3 Jiangsu Center for Collaborative Innovation in Geographical Information Resource Development and Application, Nanjing 210023, China

4 School of Karst Science, Guizhou Normal University, No.116 Baoshan North Road, Guiyang 550001, China. E-Mail: office@gznu.edu.cn

* Author to whom correspondence should be addressed; E-Mail: linzhenshan@njnu.edu.cn; Tel.: +86-138-8550-9987; Fax: +86-25-8589-1347.

Academic Editor: Marc A. Rosen

Received: 5 July 2015 / Accepted: 17 September 2015 / Published: 18 September 2015

\begin{abstract}
Guizhou Plateau is a region in China that typically shows the contradictory human-earth system. A vulnerability assessment indicator system was constructed to explore the coupled human-natural system characteristic of the karst landform based on the grey correlation analysis mathematic model. The quantitative assessment results show that Qiandongnan and Tongren Districts belong to the slight degree of the sensitivity evaluation index. Bijie district belongs to the middle degree and the other districts of Guizhou Plateau belong to the light degree. In terms of the exposure and resilience evaluation index, only Guiyang City belongs to the slight degree and other districts are in the middle degree. Thus, Guizhou Plateau could be divided into three level zones based on the comprehensive vulnerability degree of the coupled human-natural system. The strong degree vulnerability zone includes Liupanshui City, Bijie City, Anshun City, and Qiannan District. The middle degree vulnerability zone includes the districts of Qiandongnan, Qianxinan, and Tongren and the city of Zunyi. The slight degree vulnerability zone only includes Guiyang City. The research results suggest that the coupled human-natural system in Guizhou Plateau has a high vulnerability.
\end{abstract}


Keywords: grey correlation analysis modeling; coupled human-natural systems; vulnerability degree; Karst landform; Guizhou Plateau

\section{Introduction}

The impact of human actions on the natural environment continues to increase. The relationship between human and nature has become increasingly complex. We studied the human-natural coupled relationship, which has the advantage of correctly handling the relationship between human and environment. Many scholars have studied the character and mechanism of human-land relation; some have studied the evaluation indexes and methods of the relationship between human and the land. Scholars have carried out studies on the vulnerability of coupled human-natural systems and the impact of the vulnerability of human and land systems caused by natural disasters and environmental changes. Liu Jianguo et al. [1] stated that couplings between human and natural systems vary across space, time, and organizational units. Moreover, past couplings have legacy effects on the present conditions and future possibilities. Cutter et al. [2] demonstrated that social vulnerability is the product of social inequalities and defined it as the susceptibility of social groups to the impacts of hazards. Social vulnerability also means resiliency or the ability to adequately recover from these hazards. Gunderson [3] and Levin [4] studied coupled human-natural systems as complex adaptive systems. Dow [5] and Cutter [6] claimed that vulnerability has many different connotations depending on research orientation and perspective. Some scholars have studied the characteristics and mechanism of human natural system and the central components of vulnerability, namely, exposure, sensitivity, and recovery capability. Cutter, Mitchell, and Scott [7] stated that the integration of potential exposures and societal resilience specifically focuses on particular places or regions. Adger [8] proposed that the challenges for vulnerability research include the development of robust and credible measures, the incorporation of diverse methods that include perceptions of risk and vulnerability, and the integration of governance research into the mechanisms that mediate vulnerability and promote adaptive action and resilience. $\mathrm{Wu}$ [9] mentioned that the core of the human-earth areal system is the coordination of human-land relationship. Messerli [10] presented that human domination of the societies and economic environment enhances environmental vulnerability because of extreme events and human impact. Hooper et al. [11] showed that species effects are in concert with the effects of climate, resource availability, and disturbance regimes in influencing ecosystem properties. Turner et al. [12] analyzed the current situation and the development law of coupled human-natural systems by considering the stakeholders. Some scholars have studied the evaluation index and the method of the socio-ecological system vulnerability. Polsky et al. [13] constructed the vulnerability scoping diagram evaluation model and unified the concept and assessment index system. Walker and Carpenter et al. [14] proposed that the social-ecological systems determine their future trajectories by their resilience, adaptability, and transformational ability. Folke et al. [15] used the concept of resilience (the capacity to buffer, change, learn, and develop) as a framework to understand how to sustain and enhance the adaptive capacity in a complex world characterized with rapid transformations. Gunderson [16] stated that the inter-relationship of human-natural system has a strikingly different organization level. Thus, the study 
of the mechanism of the coupling between human society and natural environment remains a frontier subject. Quantitatively determining the vulnerability threshold and verifying the vulnerability degree of coupled human-natural systems are significant. However, only a few researchers have used mathematical methods to quantitatively study the vulnerability of a coupled human-natural system. Therefore, we address the issue of vulnerability by using mathematical methods.

Guizhou Plateau is located in southwest China (10336 $\left.\mathrm{6}-109^{\circ} 35^{\prime} \mathrm{E}, 24^{\circ} 37^{\prime} \mathrm{N}-29^{\circ} 13^{\prime} \mathrm{N}\right)$. With a total area of $176,100 \mathrm{~km}^{2}$, the plateau includes nine administrative districts and has a population of approximately 41,890,000. The characteristics of the plateau include the following: (1) rugged topography and wide mountainous areas; (2) high population density, serious poverty, and backward infrastructure; and (3) wide areas of karst landform and carbonate rocks and serious stony desertification ecologically situation. It is one of the most impoverished and ecology vulnerable regions in China. The carbonate rocks are widely distributed in Guizhou Plateau. Karst mountain environment is a kind of human-natural system comprising special material, energy, structure, and function (Yuan Daoxian [17]; Yang Mingde [18]; Xie Xingneng, Wang Shijie [19]). It is a typical karst landform mountain which has conspicuous contradictory between human and land. Because it is fair to assume pre-analytically that Guizhou Plateau has high vulnerability, it is plausible case to apply the method developed to measure quantitatively its vulnerability.

Gallopín [20] indicated that the central components of vulnerability are exposure, sensitivity, and capacity of response. Guizhou plateau is a typical mountain area where is conspicuous contradictory between human and land, and the ecological environment is very fragile. We follow Gallopin's characterization and, thus, understand the vulnerability of coupled-human-natural systems in Guizhou Plateau as the function of sensitivity, capacity of response, and exposure. Analyzing the correlation degree among these factors and constructing the vulnerability evaluation system based on the relational degree can lead to the realization of the quantitative analysis of vulnerability.

Hence, the vulnerability evaluation indicator system was constructed based on the grey correlation mathematics models and geography information technology. The specific method is composed of the following steps. First, the evaluation index system of coupled human-natural systems was constructed based on the three aspects of sensitivity, exposure, and resilience. Second, the data were processed in a standard manner, and entropy weight method was used to determine the weight coefficient of each index. The standardized evaluation data and the weight coefficient were integrated into the grey correlation degree model to calculate the grey relational coefficient and the grey relational degree of the sensitivity degree index, exposure degree index, and resilience index and to calculate each index dimension layer relational degree through comprehensive grey evaluation. Finally, the comprehensive evaluation and division of the degree of vulnerability of the coupled human-natural systems were taken into consideration according to the comprehensive grey correlation value. 


\section{Research Methods}

\subsection{Confirmation of Weighted Coefficient}

The concept of entropy originated from thermodynamics and statistical mechanics. It has played an important role in information theory since its introduction by Shannon [21] and has been applied in many areas. The basic calculation steps of the weighted entropy are as follows:

(1) To construct a judgment matrix:

$$
X=\left(\begin{array}{cccc}
x_{11} & x_{12} & \cdots & x_{1 n} \\
x_{21} & x_{22} & \cdots & x_{2 \mathrm{n}} \\
\cdots & \cdots & \cdots & \cdots \\
x_{m 1} & x_{m 2} & \cdots & x_{m n}
\end{array}\right) \quad \mathrm{X}=\{\mathrm{X} \mathrm{ij}\} \mathrm{m} \times \mathrm{n}(\mathrm{i}=1,2 \ldots \mathrm{m} ; \mathrm{j}=1,2 \ldots \mathrm{n})
$$

where $n$ represents the assessment objects for the matrix, and $m$ represents the evaluation indexes for each assessment object. Given that the assessment indexes systems have positive and negative types, the non-dimensional treatment for the matrix needs to be considered.

(2) Indicator standard: The maximum difference normalization method is used. The non-dimensional treatment eliminates the effects of magnitude and unit difference.

$$
y_{i j}=\frac{x_{i}-x_{\min }}{x_{\max }-x_{\min }}
$$

where the index is huge and optimal. Hence, the evaluation system of the $j_{\text {th }}$ object on the $i_{\text {th }}$ index is effective.

$$
y_{i j}=\frac{x_{\max }-x_{i}}{x_{\max }-x_{\min }}
$$

where the index is small and inefficient. Hence, the evaluation system of the $j$ th object on the $i$ th index is bad. Thus, the $X$ matrix is a transformed $Y$ matrix.

(3) The entropy of the judgment matrix and the evaluation index are determined by the formula below.

The proportion of the $j_{\text {th }}$ object on the $i_{\text {th }}$ index in the $Y$ matrix is $f i j$.

$$
f_{i j}=\frac{y_{i j}}{\sum_{i=1}^{m} y_{i j}}(j=1,2 \ldots, n)
$$

The entropy $\left(H_{j}\right)$ of the $j$ th evaluation object is:

$$
H_{j}=-\frac{1}{\ln m} \sum_{i=1}^{n} f_{i j} \ln f_{i j} \quad\left(\text { If } f_{i j}=0, \text { then define the } f_{i j} \ln f_{i j}=0\right)
$$

Thus, the weighted of the entropy of the $j$ th evaluation object is:

$$
w_{j}=\frac{1-H_{j}}{\sum_{j}^{n}\left(1-\mathrm{H}_{\mathrm{j}}\right)} \quad\left(w_{\mathrm{j}} \in[0,1], \sum_{j=1}^{n} w_{j}=1\right)
$$




\subsection{Grey Correlation Analysis Modeling}

Deng Julong [22] first proposed the grey system theory, which discusses the grey number and operation, sequence operator, prediction model, relation analysis, clustering assessment model, decision-making model and combinatorial model. It has produced the edge discipline of the grey hydrology, geology grey and grey breeding science. Grey correlation analysis modeling is a method that determines the correlation of variables and the degree of their correlation (David and Deng Julong [23]; Yi and Lina [24]). The basic steps and formula are as follows:

(1) The grey correlation coefficients $\left(\xi_{i}\right)$ are calculated.

First, the vulnerability degree assessment indexes of coupled human-land system have a maximum priority value. The priority vector $\mathrm{G}$ sequence is established as follows:

$$
G=\left(g_{1}, g_{2} \ldots g_{m}\right)=\left(y_{11} \vee y_{12} \vee \ldots \vee y_{1 m}, y_{21} \vee y_{22} \vee \ldots \vee y_{2 m}, y_{n 1} \vee y_{n 2} \vee \ldots \vee y_{n m}\right)
$$

where $\vee$ is the maximum operational symbol, $g_{i}$ is the optimal vector value of the $i_{\text {th }}$ indicator, and $y_{i j}$ is the value of the non-dimensional treatment.

Second, the correlation coefficient $\left(\xi_{i}\right)$ is calculated. The correlation coefficient of vector is between the $Y_{j}$ of the $j_{\text {th }}$ object and the priority vector $G$. The formulas are as follows:

$$
\xi_{i}\left(Y_{j}, G\right)=\frac{\min _{i} \min _{j}\left|y_{i j}-g_{i}\right|+\rho \max _{i} \max _{j}\left|y_{i j}-g_{i}\right|}{\left|y_{i j}-g_{i}\right|+\rho \max _{i} \max _{j}\left|y_{i j}-g_{i}\right|}
$$

$\rho$ is the differentiation coefficient. It diminishes the anamorphosis effect away from a big absolute error and improves the prominence difference of the obtained correlation coefficient. The value of $\rho$ is $\in(0,1)$. The distinguishing capability is best when $\rho \leq 0.563$. Generally, $\rho=0.5$ is preferable (Liu, S. F [25]; Hao [26]).

(2) The grey correlation degree is calculated. The grey correlation degree of vector $Y_{j}$ of the $j$ th object and priority vector $\mathrm{G}$ is:

$$
R_{i j}=\sum_{i=1}^{n} w_{j} \times \xi_{i}\left(\mathrm{Y}_{\mathrm{j}}, \mathrm{G}\right)
$$

where $w_{j}$ is the weight value of the $i_{\text {th }}$ indicator. The grey correlation degree is a quantitative value of the correlation among the factors. The value of grey correlation degree is higher, and the factors are more relevant.

\section{Construction of the Evaluation Framework and Indexes}

\subsection{Evaluation Index Construction}

We combined the rocky desertification ecological and environmental problems, poverty, and unique ecological environment characteristics to select and construct the evaluation index system for the coupled human-natural system in Guizhou Plateau.

The sensitivity index mainly considers the natural factors (i.e., flood, drought, and agricultural disasters) and the sensitive factor of soil erosion in karst mountainous areas. The main consideration factor is based on the aspects of the natural environmental elements (i.e., climate, landform, vegetation, soil, and hydrology). The index includes seven natural ecological indicators (Table 1). 
Exposure index mainly considers the degree of the disaster or danger of the socio-ecological system in karst mountain area and the potential loss in the event of natural disasters. The index selects the resident population density based on seven indicators (Table 1).

Resilience index reflects the mechanism and the capacity of resilience to the natural disasters of coupled human-natural systems in the karst mountain area. The index selects the per capita financial revenue based on five indicators (Table 1).

Table 1. Vulnerability assessment indexes of the coupled human-natural systems in Guizhou Plateau.

\begin{tabular}{|c|c|c|c|}
\hline $\begin{array}{c}\text { Dimension } \\
\text { Layer }\end{array}$ & Index Layer & Parameter Layer & Properties \\
\hline \multirow{7}{*}{ Sensitivity } & \multirow{2}{*}{ climate } & $\mathrm{X}_{1}$, annual mean precipitation $(\mathrm{mm})$ & + \\
\hline & & $\mathrm{X}_{2}$, annual average frost free period (d) & + \\
\hline & \multirow{2}{*}{ landforms } & $\mathrm{X}_{3}$, the proportion of mountain areas $(\%)$ & - \\
\hline & & $\mathrm{X}_{4},>25^{\circ}$ slope areas proportion $(\%)$ & - \\
\hline & plants & $\mathrm{X}_{5}$, forest coverage $(\%)$ & + \\
\hline & hydrology & $\mathrm{X}_{6}$, annual mean runoff $(\mathrm{mm})$ & + \\
\hline & soil & $\mathrm{X}_{7}$, proportion of stony desertification area (\%) & - \\
\hline \multirow{7}{*}{ Exposure } & water resources quality & $\mathrm{X}_{8}$, inferior level water quality proportion (\%) & - \\
\hline & human activities intensity & $\mathrm{X}_{9}$, unit fixed assets invested $\left(10,000 \mathrm{Yuan} / \mathrm{km}^{2}\right)$ & + \\
\hline & \multirow{2}{*}{ population } & $\mathrm{X}_{10}$, inhabitant density (people $/ \mathrm{km}^{2}$ ) & - \\
\hline & & $\mathrm{X}_{11}$, village employee proportion (\%) & - \\
\hline & \multirow{3}{*}{ economic level } & $\mathrm{X}_{12}$, per capita total output value (Yuan/person) & + \\
\hline & & $\begin{array}{l}\mathrm{X}_{13} \text {, unit total output value of energy consumption } \\
\text { (tons of } \mathrm{SCE} / 10000 \text { yuan) }\end{array}$ & - \\
\hline & & $\mathrm{X}_{14}$, incidence of rural poverty $(\%)$ & - \\
\hline \multirow{5}{*}{ Resilience } & government financial strength & $\mathrm{X}_{15}$, per capita financial revenue (Yuan/person) & + \\
\hline & social security & $\mathrm{X}_{16}$, medical staff per thousand (person/1000 person) & + \\
\hline & \multirow{3}{*}{ educational level } & $\mathrm{X}_{17}$, locality university student's proportion (\%) & + \\
\hline & & $\mathrm{X}_{18}$, internet proportion (\%) & + \\
\hline & & $\mathrm{X}_{19}$, road net density $\left(\mathrm{km} / \mathrm{km}^{2}\right)$ & + \\
\hline
\end{tabular}

Note: "+" represents the positive index; "-" represent the negative index.

\subsection{Index Evaluation Framework Construction}

The evaluating framework includes three dimensions, namely, sensibility, exposure, and resilience (Table 1). The framework includes 19 assessment indicators of the nine districts in Guizhou Plateau. Data were acquired through the remote sensing image processing and the statistical bulletin of the provincial government of Guizhou (Table 2). 
Table 2. Data of vulnerability assessment indexes of the coupled human-natural systems in Guizhou Plateau.

\begin{tabular}{|c|c|c|c|c|c|c|c|c|c|}
\hline Index Level & & & & & District & & & & \\
\hline $\begin{array}{c}\text { Parameter } \\
\text { Layer }\end{array}$ & Guiyang & Liupanshui & Zunyi & Anshun & Tongren & Bijie & Qianxinan & Qiandongnan & Qiannan \\
\hline $\mathrm{X}_{1}$ & 1095.7 & 1315.8 & 1077 & 1275 & 1228.6 & 1023.3 & 1273.3 & 1235.8 & 1235.3 \\
\hline $\mathrm{X}_{2}$ & 270 & 250 & 285 & 245 & 220 & 240 & 300 & 240 & 280 \\
\hline $\mathrm{X}_{3}$ & 40.1 & 66.7 & 61.9 & 46.8 & 64.1 & 57.8 & 62.8 & 72.8 & 60.4 \\
\hline $\mathrm{X}_{4}$ & 5.77 & 13.83 & 14.71 & 19.99 & 20.71 & 10.54 & 36.23 & 31.29 & 26.88 \\
\hline $\mathrm{X}_{5}$ & 42.3 & 38 & 48.6 & 39 & 49.8 & 41.5 & 46 & 63 & 53.76 \\
\hline $\mathrm{X}_{6}$ & 561.9 & 542.9 & 560.4 & 670.9 & 697.8 & 500.5 & 677.2 & 633.1 & 620.5 \\
\hline $\mathrm{X}_{7}$ & 23.36 & 32.94 & 15.19 & 32.04 & 18.18 & 26.1 & 29.94 & 5.88 & 29.46 \\
\hline $\mathrm{X}_{8}$ & 25.1 & 8.2 & 18.3 & 4.2 & 44.3 & 2.3 & 5.9 & 34.5 & 17.2 \\
\hline $\mathrm{X}_{9}$ & 1763.28 & 443.89 & 222.78 & 178.66 & 166.64 & 234.92 & 179.23 & 115.55 & 152.72 \\
\hline $\mathrm{X}_{10}$ & 546.43 & 287.47 & 198.3 & 246.03 & 171.08 & 242.8 & 166.63 & 114.05 & 122.55 \\
\hline $\mathrm{X}_{11}$ & 26.97 & 49.09 & 65.64 & 62.92 & 72.94 & 68.97 & 65.55 & 69.39 & 67.07 \\
\hline $\mathrm{X}_{12}$ & $31,712.39$ & 21,522 & $18,335.05$ & $12,472.14$ & $11,621.95$ & $11,294.97$ & $13,385.75$ & $11,047.48$ & $13,765.12$ \\
\hline $\mathrm{X}_{13}$ & 1.42 & 2.83 & 1.34 & 2.13 & 1.64 & 1.88 & 1.71 & 1.92 & 1.77 \\
\hline $\mathrm{X}_{14}$ & 16.8 & 38.3 & 21.85 & 30.79 & 38.75 & 35.54 & 36.23 & 42.11 & 36 \\
\hline $\mathrm{X}_{15}$ & 4291.49 & 2468.22 & 1383.49 & 1157.47 & 919.22 & 1236.26 & 1622.82 & 1303.67 & 1216.41 \\
\hline $\mathrm{X}_{16}$ & 7.61 & 2.9 & 2.66 & 2.18 & 1.81 & 1.49 & 2.25 & 2.46 & 2.4 \\
\hline $\mathrm{X}_{17}$ & 6.31 & 0.27 & 0.8 & 0.62 & 0.45 & 0.25 & 0.41 & 0.75 & 0.65 \\
\hline $\mathrm{X}_{18}$ & 0.81 & 0.44 & 0.43 & 0.4 & 0.33 & 0.3 & 0.41 & 0.43 & 0.39 \\
\hline $\mathrm{X}_{19}$ & 1.15 & 1.2 & 0.78 & 1 & 1.19 & 0.93 & 0.49 & 1.59 & 0.59 \\
\hline
\end{tabular}

The sensitivity indexes of the regional coupled human-natural systems indicated that the probability of the natural environment mutation event was transformed into a catastrophic event. The exposure indexes that reflected the regional social system showed a degree of natural disaster when natural environment mutated. Luthar and Cicchetti [27] claimed that the exposure of the coupled human -natural system is the impaired degree for the environment change of a locality, region, or globe. The resilience indexes reflected the ability of the regional social system to derive feedback on natural disasters when the natural environment was mutating. Waker [28] explained that resilience maintains the same structure and function and sustained development ability when the coupled human-natural system is disturbed.

\section{Calculation}

\subsection{Calculation of Weight Coefficient and Evaluation Index Value}

The data derived through Equations (1) or (2) (Table 2) were used to obtain the standard data (Table 3). The data obtained through Equations (3)-(5) were used to obtain the weight value $\left(w_{j}\right)$ of the dimension layer and the parameter index (Table 4). The weight value was used to multiply the non-dimensional standard value. The value of every dimension layer of the nine districts in Guizhou Plateau (Table 5) was then obtained. Every indicator has same important role for the assessment 
system based on Table 4. The value of every dimension layer was analyzed. The sensitivity evaluation index values are small, and the natural ecological environment quality is poor.

Table 3. Non-dimensional standard value of the vulnerability assessment index in Guizhou Plateau.

\begin{tabular}{|c|c|c|c|c|c|c|c|c|c|}
\hline \multirow{2}{*}{$\begin{array}{c}\text { Index Level } \\
\text { Parameter } \\
\text { Layer } \\
\end{array}$} & \multicolumn{9}{|c|}{ District } \\
\hline & Guiyang & Liupanshui & Zunyi & Anshun & Tongren & Bijie & Qianxinan & Qiandongnan & Qiannan \\
\hline $\mathrm{X}_{1}$ & 0.2475 & 1.0000 & 0.1836 & 0.8605 & 0.7019 & 0.0000 & 0.8547 & 0.7265 & 0.7248 \\
\hline $\mathrm{X}_{2}$ & 0.6250 & 0.3750 & 0.8125 & 0.3125 & 0.0000 & 0.2500 & 1.0000 & 0.2500 & 0.7500 \\
\hline $\mathrm{X}_{3}$ & 1.0000 & 0.1865 & 0.3306 & 0.3333 & 0.7951 & 0.2661 & 0.3058 & 0.0000 & 0.3792 \\
\hline $\mathrm{X}_{4}$ & 1.0000 & 0.7354 & 0.7065 & 0.5332 & 0.5095 & 0.8434 & 0.0000 & 0.1622 & 0.3070 \\
\hline $\mathrm{X}_{5}$ & 0.1720 & 0.0000 & 0.4240 & 0.0400 & 0.4720 & 0.1400 & 0.3200 & 1.0000 & 0.6304 \\
\hline $\mathrm{X}_{6}$ & 0.3112 & 0.2149 & 0.3036 & 0.8637 & 1.0000 & 0.0000 & 0.8956 & 0.6721 & 0.6082 \\
\hline $\mathrm{X}_{7}$ & 0.3540 & 0.0000 & 0.6559 & 0.0333 & 0.5455 & 0.2528 & 0.1109 & 1.0000 & 0.1286 \\
\hline $\mathrm{X}_{8}$ & 0.4571 & 0.8595 & 0.6190 & 0.9548 & 0.0000 & 1.0000 & 0.9143 & 0.2333 & 0.6452 \\
\hline $\mathrm{X}_{9}$ & 1.0000 & 0.1993 & 0.0651 & 0.0383 & 0.0310 & 0.0724 & 0.0386 & 0.0000 & 0.0226 \\
\hline $\mathrm{X}_{10}$ & 1.0000 & 0.4011 & 0.1948 & 0.3053 & 0.1319 & 0.2978 & 0.1216 & 0.0000 & 0.0197 \\
\hline $\mathrm{X}_{11}$ & 1.0000 & 0.5188 & 0.1588 & 0.2180 & 0.0000 & 0.0864 & 0.1608 & 0.0772 & 0.1277 \\
\hline $\mathrm{X}_{12}$ & 1.0000 & 0.5069 & 0.3527 & 0.0689 & 0.0278 & 0.0120 & 0.1132 & 0.0000 & 0.1315 \\
\hline $\mathrm{X}_{13}$ & 0.9493 & 0.0000 & 1.0020 & 0.4672 & 0.8007 & 0.6407 & 0.7523 & 0.6079 & 0.7081 \\
\hline $\mathrm{X}_{14}$ & 1.0000 & 0.1505 & 0.8005 & 0.4473 & 0.1328 & 0.2596 & 0.2323 & 0.0000 & 0.2414 \\
\hline $\mathrm{X}_{15}$ & 1.0000 & 0.4593 & 0.1377 & 0.0706 & 0.0000 & 0.0940 & 0.2086 & 0.1140 & 0.0881 \\
\hline $\mathrm{X}_{16}$ & 1.0000 & 0.2311 & 0.1916 & 0.1129 & 0.0515 & 0.0000 & 0.1241 & 0.1583 & 0.1487 \\
\hline $\mathrm{X}_{17}$ & 1.0000 & 0.0033 & 0.0908 & 0.0611 & 0.0330 & 0.0000 & 0.0264 & 0.0825 & 0.0660 \\
\hline $\mathrm{X}_{18}$ & 0.9982 & 0.2811 & 0.2546 & 0.1932 & 0.0616 & 0.0000 & 0.2198 & 0.2538 & 0.1755 \\
\hline $\mathrm{X}_{19}$ & 0.5973 & 0.6461 & 0.2645 & 0.4598 & 0.6407 & 0.3973 & 0.0034 & 1.0000 & 0.0946 \\
\hline
\end{tabular}

Table 4. Weight value of the vulnerability assessment index of the coupled human-natural system.

\begin{tabular}{|c|c|c|c|c|c|}
\hline \multicolumn{2}{|c|}{ Sensitivity $\left(w_{j}=0.2734\right)$} & \multicolumn{2}{|c|}{ Exposure $\left(w_{j}=0.3918\right)$} & \multicolumn{2}{|c|}{ Resilience $\left(w_{j}=0.3348\right)$} \\
\hline Parameters & Weighting $\left(w_{j}\right)$ & Parameters & Weighting $\left(w_{j}\right)$ & Parameters & Weighting $\left(w_{j}\right)$ \\
\hline $\mathrm{X}_{1}$ & 0.0978 & $\mathrm{X}_{8}$ & 0.0595 & $\mathrm{X}_{15}$ & 0.1960 \\
\hline $\mathrm{X}_{2}$ & 0.1055 & $\mathrm{X}_{9}$ & 0.2953 & $\mathrm{X}_{16}$ & 0.1895 \\
\hline $\mathrm{X}_{3}$ & 0.1191 & $\mathrm{X}_{10}$ & 0.1397 & $\mathrm{X}_{17}$ & 0.3818 \\
\hline $\mathrm{X}_{4}$ & 0.0982 & $\mathrm{X}_{11}$ & 0.1513 & $\mathrm{X}_{18}$ & 0.1413 \\
\hline $\mathrm{X}_{5}$ & 0.1624 & $\mathrm{X}_{12}$ & 0.1999 & $\mathrm{X}_{19}$ & 0.0913 \\
\hline $\mathrm{X}_{6}$ & 0.2320 & $\mathrm{X}_{13}$ & 0.0465 & - & - \\
\hline $\mathrm{X}_{7}$ & 0.1851 & $\mathrm{X}_{14}$ & 0.1076 & - & - \\
\hline
\end{tabular}

Hence, the sensitivity of the index value is small, the natural ecological environment is in bad condition, and the ability to maintain the stability of the environment is weak. The exposure index value is low, which indicates that the disaster and risk is more on the human system. The resilience ability value is high, the adaptability to natural environment mutation and disaster is strong, and management and control of the human land system are socially strong. 
Table 5. Evaluation index value of each assessment dimension of the nine districts in Guizhou Plateau.

\begin{tabular}{ccccccccccc}
\hline \multirow{2}{*}{ Dimension Index } & \multicolumn{10}{c}{ district } \\
& Guiyang & Liupanshui & Zunyi & Anshun & Tongren & Bijie & Qianxiana & Qiandongnan & Qiannan \\
\hline Sensitivity & 0.4731 & 0.2816 & 0.4731 & 0.4221 & 0.6229 & 0.2104 & 0.5057 & 0.6167 & 0.4926 \\
Exposure & 0.9653 & 0.3109 & 0.2738 & 0.1706 & 0.0847 & 0.1362 & 0.1354 & 0.0400 & 0.1140 \\
Resilience & 0.9631 & 0.2338 & 0.1581 & 0.1279 & 0.0896 & 0.0547 & 0.1059 & 0.2111 & 0.1041 \\
\hline
\end{tabular}

Table 5 shows that the values of the sensitivity indexes in Guizhou Plateau are relatively small, and those in Liupanshui City and Bijie City are smaller. These findings indicate that the stability of the coupled human-natural system was under external interference. The exposure value $(0.9653)$ and resilience value (0.9631) of Guiyang City are very high, but the values of others districts are very low. Hence, the coupled human-natural system of Guiyang City is better than those of the other districts in Guizhou Plateau.

\subsection{Calculation of the Grey Correlation Degree}

\subsubsection{Calculation of the Grey Relational Coefficients}

Table 3 confirms that the maximum priority value of every assessment index is 1 , based on Equation (6). The values of the maximum priority and the non-dimensional standard data (Table 3) were incorporated into Equation (7). The grey correlation coefficient $\left(\xi_{i}\right)$ was then obtained (Table 6).

Table 6. Value of grey correlation coefficient $\left(\xi_{\mathrm{i}}\right)$ of the coupled human-natural system in Guizhou Plateau.

\begin{tabular}{|c|c|c|c|c|c|c|c|c|c|c|}
\hline \multicolumn{2}{|c|}{ Index } & \multicolumn{9}{|c|}{ District } \\
\hline $\begin{array}{c}\text { Dimension } \\
\text { Layer }\end{array}$ & Parameters & Guiyang & Liupanshui & Zunyi & Anshun & Tongren & Bijie & Qianxiana & Qiandongnan & Qiannan \\
\hline \multirow{7}{*}{ Sensitivity } & $\mathrm{X}_{1}$ & 0.3992 & 1.0000 & 0.3798 & 0.7819 & 0.6265 & 0.3333 & 0.7748 & 0.6464 & 0.6450 \\
\hline & $\mathrm{X}_{2}$ & 0.5714 & 0.4444 & 0.7273 & 0.4211 & 0.3333 & 0.4000 & 1.0000 & 0.4000 & 0.6667 \\
\hline & $\mathrm{X}_{3}$ & 1.0000 & 0.3807 & 0.4276 & 0.4286 & 0.7093 & 0.4052 & 0.4187 & 0.3333 & 0.4461 \\
\hline & $\mathrm{X}_{4}$ & 1.0000 & 0.6539 & 0.6301 & 0.5171 & 0.5048 & 0.7615 & 0.3333 & 0.3737 & 0.4191 \\
\hline & $\mathrm{X}_{5}$ & 0.3765 & 0.3333 & 0.4647 & 0.3425 & 0.4864 & 0.3676 & 0.4237 & 1.0000 & 0.5750 \\
\hline & $\mathrm{X}_{6}$ & 0.4206 & 0.3891 & 0.4179 & 0.7857 & 1.0000 & 0.3333 & 0.8273 & 0.6039 & 0.5607 \\
\hline & $\mathrm{X}_{7}$ & 0.4363 & 0.3333 & 0.5924 & 0.3409 & 0.5238 & 0.4009 & 0.3599 & 1.0000 & 0.3646 \\
\hline \multirow{7}{*}{ Exposure } & $\mathrm{X}_{8}$ & 0.4795 & 0.7807 & 0.5676 & 0.9170 & 0.3333 & 1.0000 & 0.8537 & 0.3947 & 0.5850 \\
\hline & $\mathrm{X}_{9}$ & 1.0000 & 0.3844 & 0.3485 & 0.3421 & 0.3404 & 0.3502 & 0.3421 & 0.3333 & 0.3384 \\
\hline & $\mathrm{X}_{10}$ & 1.0000 & 0.4550 & 0.3831 & 0.4185 & 0.3655 & 0.4159 & 0.3627 & 0.3333 & 0.3378 \\
\hline & $\mathrm{X}_{11}$ & 1.0000 & 0.5096 & 0.3728 & 0.3900 & 0.3333 & 0.3537 & 0.3733 & 0.3514 & 0.3643 \\
\hline & $\mathrm{X}_{12}$ & 1.0000 & 0.5035 & 0.4358 & 0.3494 & 0.3396 & 0.3360 & 0.3605 & 0.3333 & 0.3654 \\
\hline & $\mathrm{X}_{13}$ & 0.9079 & 0.3333 & 1.0041 & 0.4841 & 0.7150 & 0.5818 & 0.6687 & 0.5605 & 0.6314 \\
\hline & $\mathrm{X}_{14}$ & 1.0000 & 0.3705 & 0.7148 & 0.4749 & 0.3657 & 0.4031 & 0.3944 & 0.3333 & 0.3973 \\
\hline \multirow{5}{*}{ Resilience } & $\mathrm{X}_{15}$ & 1.0000 & 0.4805 & 0.3670 & 0.3498 & 0.3333 & 0.3556 & 0.3872 & 0.3608 & 0.3541 \\
\hline & $\mathrm{X}_{16}$ & 1.0000 & 0.3940 & 0.3821 & 0.3605 & 0.3452 & 0.3333 & 0.3634 & 0.3727 & 0.3700 \\
\hline & $\mathrm{X}_{17}$ & 1.0000 & 0.3341 & 0.3548 & 0.3475 & 0.3408 & 0.3333 & 0.3393 & 0.3527 & 0.3487 \\
\hline & $\mathrm{X}_{18}$ & 0.9964 & 0.4102 & 0.4015 & 0.3826 & 0.3476 & 0.3333 & 0.3906 & 0.4012 & 0.3775 \\
\hline & $\mathrm{X}_{19}$ & 0.5539 & 0.5856 & 0.4047 & 0.4807 & 0.5819 & 0.4535 & 0.3341 & 1.0000 & 0.3558 \\
\hline
\end{tabular}




\subsubsection{Calculation of the Grey Correlation Degree $\left(R_{i j}\right)$}

The grey correlation degree $\left(R_{i j}\right)$ represents the mutually closer degree between human activity action and natural environment. The value is smaller, and the vulnerability of coupled human-natural system is more serious. The different regional rankings in Guizhou Plateau can be obtained after the grey correlation degree $\left(R_{i j}\right)$ is calculated.

The correlation coefficient value $\left(\xi_{i}\right)$ and the weight value of assessment indicators $\left(w_{j}\right)$ were incorporated into Equation (7) to obtain the grey correlation degree value $\left(R_{i j}\right)$. Thus, the standard matrix of the correlation degree values of the 19 assessment indexes of nine districts in Guizhou Plateau was obtained (Table 7). The same steps used to acquire the comprehensive grey correlation degree value of the nine districts in Guizhou Plateau were considered (bottom of Table 7).

\subsubsection{Ranking the grey correlation degree}

The grey correlation degrees for the evaluation index system were ranked based on a long-term study in karst mountain areas. The main division bases were the natural environment condition, resource, socioeconomic condition, infrastructure, and population pressure (Table 8). The results are shown in Table 7.

Table 7. Correlation degree $\left(R_{i j}\right)$ and vulnerability degree of coupled human-natural system.

\begin{tabular}{|c|c|c|c|c|c|c|c|c|c|c|}
\hline layer & $\begin{array}{c}\text { Correlation } \\
\text { Degree } \\
\end{array}$ & Guiyang & Liupanshui & Zunyi & Anshun & Tongren & Bijie & Qianxinan & Qiandongnan & Qiannan \\
\hline \multirow{5}{*}{$\begin{array}{l}\text { the first step } \\
\text { evaluation }\end{array}$} & $R_{\text {sensitivity }}$ & 0.6885 & 0.6097 & 0.6674 & 0.6678 & 0.7583 & 0.5720 & 0.7149 & 0.7722 & 0.6767 \\
\hline & vulnerability rank & light & light & light & light & slight & middle & light & slight & light \\
\hline & $R_{\text {exposure }}$ & 0.9382 & 0.5689 & 0.5699 & 0.5211 & 0.4983 & 0.5110 & 0.5114 & 0.4834 & 0.5489 \\
\hline & $R_{\text {resilience }}$ & 0.9735 & 0.5753 & 0.5424 & 0.5365 & 0.5295 & 0.5162 & 0.529 & 0.5782 & 0.5277 \\
\hline & vulnerability rank & slight & middle & middle & middle & middle & middle & middle & middle & middle \\
\hline the second step & $R_{\text {comprehensive }}$ & 0.9409 & 0.4060 & 0.4568 & 0.4242 & 0.5304 & 0.3639 & 0.4667 & 0.5012 & 0.4365 \\
\hline evaluation & vulnerability rank & slight & strong & middle & strong & middle & strong & middle & middle & strong \\
\hline
\end{tabular}

Table 8. Rank and property of the vulnerability coupled human-natural system in Guizhou Plateau.

\begin{tabular}{cll}
\hline \multicolumn{1}{c}{ Grades } & Value & \multicolumn{1}{c}{ Properties } \\
\hline acute vulnerability & $0-0.30$ & $\begin{array}{l}\text { Live environment extremely worst; natural affect acute; environment } \\
\text { vulnerable strong; soc-economy extremely backward; human-natural system } \\
\text { self-recovery lowness }\end{array}$ \\
\hline strong vulnerability & $0.3-0.45$ & $\begin{array}{l}\text { Live environment relatively worst; environment vulnerable intensity; } \\
\text { soc-economy very backward; human-natural system self-recovery lowness }\end{array}$ \\
\hline middle vulnerability & $0.45-0.60$ & $\begin{array}{l}\text { Live environment common; environment vulnerable lightly; soc-economy } \\
\text { level backward; human-natural system have some self-recovery ability }\end{array}$ \\
\hline light vulnerability & $0.60-0.75$ & $\begin{array}{l}\text { Live environment good; soc-economy level high; human-natural system have } \\
\text { evident self-recovery ability }\end{array}$ \\
\hline slight vulnerability & $0.75-1.0$ & $\begin{array}{l}\text { Live environment very good; soc-economy level very high; human-natural } \\
\text { system have strong self-recovery ability }\end{array}$ \\
\hline
\end{tabular}




\section{Zoning and Results Analyses}

The quantitative assessment values of every district show that Guizhou Plateau could be divided into three vulnerability coupled human-natural system zones. Western, west center, southern, and northwest belong to the strong vulnerability degree zone. Eastern, northeast, southeast, and southwest belong to the middle vulnerability degree zone. The central area of Guizhou Plateau belongs to the slight vulnerability degree zone (Figure 1).

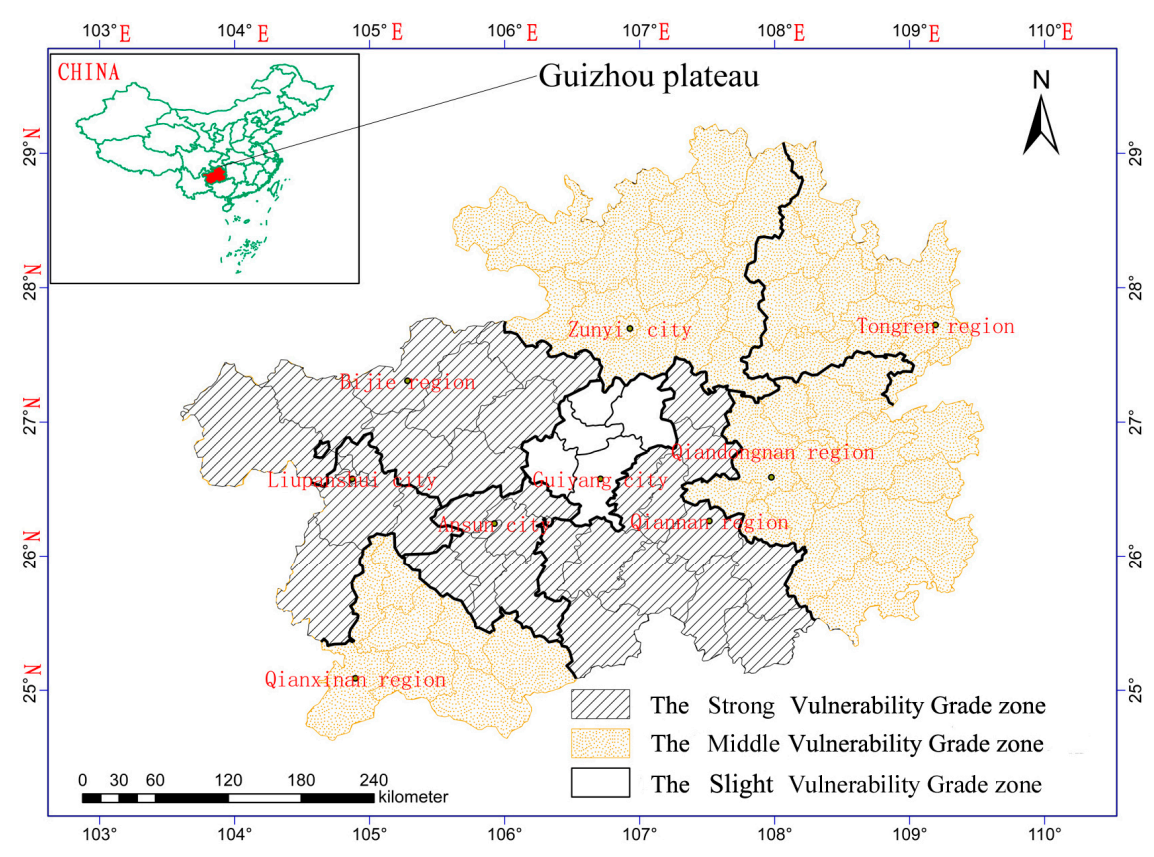

Figure 1. Vulnerability grade zone of coupled human-natural system in Guizhou Plateau.

\subsection{Strong Vulnerability Degree Zone}

The coupled characteristics of human-natural systems in this zone can be described as follows: (1) Liupanshui City's average elevation is more than $1800 \mathrm{~m}$. Its terrain is broken, and the steep slope proportion is high. The stony desertification degree is significantly high (32.94\%), and forest coverage is considerably low. The regional economy mainly depends on coal and other mineral resources, and the medical, education, and transportation infrastructure is very poor. The resident population density (287.47 people $/ \mathrm{km}^{2}$ ) and rural poverty rate are considerably high (38.30\%). (2) Bijie City was named as an experimental area by the State Council of China to alleviate poverty and improve ecology. The land stony desertification question is serious (26.10\%), and the mountain area is large. The regional economy mainly depends on agricultural production. The population density $\left(242.80\right.$ people $\left./ \mathrm{km}^{2}\right)$ and the rural poverty rate are notably high (35.54\%). (3) Anshun city's $>25^{\circ}$ slope land area is large (19.99\%). The land stony desertification is significantly serious $(32.04 \%)$. The population density (246.03 people $/ \mathrm{km}^{2}$ ) and rural poverty rate are considerably high $(30.79 \%)$. The regional economy depends on the agricultural production, and infrastructure is backward. (4) The terrain fragmentation of Qiannan District is very high. The mountain area is large, and the $>25^{\circ}$ slope area proportion is high (26.88\%). The land stony desertification area proportion is high (29.46\%), and soil erosion is very 
serious. The economic development level is significantly low and the agricultural poverty rate is considerably high (36\%). The communication, medical, and transportation infrastructure is backward.

The ecological environment stroma systems of the four regions are relatively fragile. These areas are faced with evident human-land contradiction and serious ecological questions because of the disturbance caused by climate change, natural calamities, poverty, and unreasonable human activities (Zhang Baiping, [29]). Intensity degree of rocky desertification phenomenon, rugged terrain, the fragile karst ecosystem, led to very significant sensitivity of the human-natural system of the regions (Ouyang Zhiyuan, [30]). The poor infrastructure and low socio-economic level that leads to the resilience of human-natural system is very weak (Ortega, [31]). Thus, a highly sensitive and high degree of exposure of the human-natural relationship and the strong vulnerability degree of the coupled human-natural system were formed.

\subsection{Middle Vulnerability Degree Zone}

The coupled characteristics of human-land system in these regions include the following: (1) the proportions of Qiandongnan District's mountain areas are the highest $(72.8 \%)$, and the $>25^{\circ}$ slope of land area proportion is significantly high (31.29\%). However, the proportion of the stony desertification areas is the lowest (5.88\%), and the forest coverage is the highest (63\%). The resident population density is low (114.05 people $\left./ \mathrm{km}^{2}\right)$, and the rural working population proportion is notably high $(69.39 \%)$. The rural poverty rate is the highest (42.11\%). The regional economy mainly depends on agriculture, forestry, and tourism. The medical, education, and transportation infrastructure is considerably poor. (2) The proportion of the Qianxinan district's mountain areas is significantly high $(62.8 \%)$, and the $>25^{\circ}$ slope of land area proportion is likewise high $(36.23 \%)$. The proportion of the stony desertification areas proportion is moderate $(29.94 \%)$ and the forest coverage is low. The proportion of rural working population is very high $(65.55 \%)$, and the rural poverty rate is high (36.23\%). The regional economy mainly depends on agriculture, tourism, and mineral resources. The infrastructure is backward. (3) Zunyi City's mountain area is large. However, the proportion of the $>25^{\circ}$ slope of land area is low (14.71\%). The proportion of the stony desertification areas is low (15.19\%), and the resident population density is high (198.30 people $\left./ \mathrm{km}^{2}\right)$. The population of the rural working population is significantly high $(65.64 \%)$, and the man-land contradiction is obvious. The regional economy mainly depends on agricultural production, mineral resources, and tourism. The infrastructure for health care, education, and transportation is relativity good. (4) Tongren District's mountain area is large $(64.1 \%)$. The proportion of the $>25^{\circ}$ slope of land area $(20.71 \%)$ is moderate. The proportion of the stony desertification area is medium (18.18\%), and the forest coverage is high (49.8\%). The resident population density is high $\left(171.08\right.$ people $\left./ \mathrm{km}^{2}\right)$. The rural working population proportion is considerably high (72.94\%), and the rural poverty rate is likewise notably high (38.75\%).

The rocky desertification area in these regions is relatively small. Terrain conditions are relatively good. The proportion of the mountain area and the $>25^{\circ}$ slope cultivated land area are relatively high. The natural environment situation is more conducive to life; the structural features of the human-natural system are relatively more stable. As a result, its sensitivity is weaker than those of the areas within the strong vulnerability degree zone. However, the regional man-land contradictions are evident, and the economic development level is low. Meanwhile, a large number of mineral resources exploitation, ecological destruction, and environmental pollution leads to an increase in the exposure 
risk of the human-natural system. Thus, these areas form the middle vulnerability degree of the coupled human-natural system.

\subsection{Slight Vulnerability Degree Zone}

Guiyan City is the provincial capital of Guizhou Province, which is located in the center platform terrain region of Guizhou Plateau. The rocky desertification area in the region is the smallest, terraced terrain is relatively flat, and soil quality is better. Therefore, the system structure of Guiyang City is the most stable and the critical value of its damaged system is highest too. Its economic, political, and cultural development levels are the highest in Guizhou Plateau. The communication and transportation are good, and the geographic location is superior. Thus, Guiyang City has light sensitivity vulnerability rank, slight exposure vulnerability rank, and strong resilience ability. They constitute the human-natural system structure that is more stable and less subject to the impact of various types of disasters (Zhang Dianfa, [32]). Therefore, Guiyang City has the most stable coupled human-natural system relation in Guizhou Plateau.

Comprehensive analysis shows that the sensitivity is determined by the karst landform system characteristics and the critical condition of karst ecological system that was destroyed in Guizhou Plateau. Exposure reflects the degree of outside interference or intimidation (Polsky, [14]). Unreasonable human activity is the main driving force of karst ecosystem degradation, which also leads to the evident increase in the exposure degree of human-natural system. Therefore, controlling the rapid growth of population, strengthening the construction of infrastructure (i.e., traffic, communication, education) through the development of tourism and other measures that promote local social and economic development, improving the level of government management, and cultivating awareness of ecological environment protection and sustainable development, are important measures that could strengthen the resilience ability of the coupled human-natural system.

\section{Conclusions}

Recent integrated studies of coupled human-natural systems reveal new and complex patterns and processes in space and time. Vulnerability problems that have been the concern of limited fields (i.e., earth science and environmental science) have gradually expanded to the multiple aspects of the development of human society. The interaction between human and natural system, the complex characteristics of coupled human-natural systems, and the vulnerability of the natural environment and human society have all been studied and verified through literature reviews. Guizhou Plateau is a typical karst mountainous area with a highly conspicuous contradiction between humans and the earth. The complex coupled human-natural systems and the vulnerability of socio-ecological system have also been verified through literature reviews. Therefore, the authors developed vulnerability evaluation indexes and used the entropy weight method and grey relational mathematical model to study the vulnerability degree rank of coupled human-natural systems.

The contributions of this research include the effective evaluation index system of the vulnerability and the efficient mathematical model that quantitatively evaluated the vulnerability of the coupled human-natural systems in the typical karst mountainous area. Second, the evaluation index values (i.e., the weight value used to multiply the non-dimensional standard value) of sensitivity, exposure, 
and resilience have the capability to reflect the interaction between natural environment and human activities, as revealed by the results. The sensitivity index value reflects the stability of the natural environment system. The exposure index value reflects the degree of disaster in the human earth system. The resilience index value reflects the human control ability on human earth system. Third, the grey correlation $\left(R_{i j}\right)$ has proven to be able to reflect the mutual closeness of the evaluation index and optimal index mutual. Therefore, it can reflect the coupling state and vulnerability degree of coupled human-natural systems. Finally, we divided Guizhou Plateau into three vulnerability coupled human-natural system zones and took comprehensive analysis for it, which shows that these research methods are scientific.

This study is significant given that a mathematical model for the quantitative evaluation of the vulnerability of coupled human-natural systems has been successfully applied to understand vulnerability of the karst mountainous area in Guizhou Plateau. Hence, it offers a new tool that can be used in future research on the vulnerability characteristics of coupled human-natural systems, assist in the addressing rocky desertification and ecological environment problems. The results show that if we want to address the vulnerability of coupled human-natural systems, we must improve the regional ecological environment and strengthen the sensitivity of the natural environment to human activities. The exposure of the coupled human-natural system must be reduced to lessen the suffering during natural disasters caused by human activities. The development of the economy, improvement of regional infrastructure and cultural quality, and the increase in the adaptability and resilience of coupled human-natural systems must be continued.

Nevertheless, this research is limited because the evaluation index system has not been perfected. The evaluation of the different regions is different. Thus, the effect of subjective choice is evident. Qualitative methods and data analysis data are not perfect. More information is needed to obtain accurate evaluation.

\section{Acknowledgments}

The authors would like thank the support of their colleagues in Guizhou government department. This research is a component of the China Nation "Twelfth Five" Science and Technology Support Program Major Issue Project "Karst plateau canyon stony desertification comprehensive treatment technology and demonstration" (2011BAC09B01). We are very thankful for the additional funding provided by Guizhou Province Science and Technology Department "Study on ecological compensation mechanism of Qing shuijiang watershed basin based on the main function division" ([2014]7237). We are also wish to thank the other grant participants for their valuable contributions.

\section{Author Contributions}

All authors read and approved the final manuscript. He Xiang wrote and revised the manuscript and participated in designing the study. Lin Zhen Shan provided directed the study and revised the manuscript's final version. Xiong Kong Ning designed the study, interpreted the data and participated in writing the manuscript. 


\section{Conflicts of interest}

The authors declare no conflict of interest.

\section{References}

1. Liu, J.G.; Dietz, T.; Carpenter, S.R.; Alberti, M.; Folke, C.; Moran, E.; Pell, A.N.; Deadman, P.; Kratz, T.; Lubchenco, J.; et al. Complexity of coupled human and natural systems. Science 2007, 317, 1513-1516.

2. Cutter, S.L.; Christopher, T.E. Moral hazard, social catastrophe: The changing face of vulnerability along the hurricane coasts. Ann. Am. Acad. Polit. Soc. Sci. 2006, 604, 102-112.

3. Gunderson, L.H.; Holling, C.S. Panarchy: Understanding Transformations in Human and Natural Systems; Island Press: Washington, DC, USA, 2002.

4. Levin, S.A.; Dominion, F. Complexity and the Commons; Perseus Books: Reading, MA, USA, 1999.

5. Dow, K. Exploring Differences in Our Common Future(s): The Meaning of Vulnerability to Global Environmental Change. Geoforum 1992, 23, 417-436.

6. Cutter, S.L.; Boruff, B.J.; Shirley, W.L. Social Vulnerability to Environmental Hazards. Soc. Sci. Q. 2003, 84, 242-261.

7. Cutter, S.L.; Mitchell, J.T.; Scott, M.S. Revealing the Vulnerability of People and Places: A Case Study of Georgetown County, South Carolina. Ann. Assoc. Am. Geogr. 2000, 90, 713-737.

8. Adger, W.N. Vulnerability. Glob. Environ. Chang. 2006, 16, 268-281.

9. Wu, C.J. The research core on geography of the man-earth areal system. Econ. Geogr. 1991, doi:10.15957/j.cnki.jjdl.1991.03.001. (In Chinese)

10. Messerli, B.; Grosjean, M.; Hofer, T. From nature-dominated to human-dominated environmental changes. Q. Sci. Rev. 2000, 19, 459-479.

11. Hooper, D.U.; Chapin, F.S., III; Ewel, J.J. Effects of biodiversity on ecosystem function: A consensus of current knowledge. Ecol. Monogr. 2005, 75, 3-35.

12. Turner, B.L.; Kasperson, R.E.; Matson, P.A. A framework for vulnerability analysis in sustainability science. Proc. Natl. Acad. Sci. USA 2003, 100, 8074-8079.

13. Polsky, C.; Neff, R.; Yarnal, B. Building comparable global change vulnerability assessments: The vulnerability scoping diagram. Glob. Environ. Chang. 2007, 17, 472-485.

14. Walker, B.; Carpenter, S.; Anderies, J.; Abel, N.; Cumming, G.; Janssen, M.; Lebel, L.; Norberg, J.; Peterson, G.D.; Pritchard, R. Resilience management in social-ecological systems: A working hypothesis for a participatory approach. Conserv. Ecol. 2002, 6, Article 14.

15. Folke, C.; Carpenter, S.R.; Elmqvist, T.; Gunderson, L.; Holling, C.S. Resilience and sustainable development: Building adaptive capacity in a world of transformations. AMBIO 2002, 31, 437-440.

16. Gunderson, L.H. Ecological resilience-in theory and application. Ann. Rev. Ecol. Syst. 2000, 31, 425-439.

17. Yuan, D.X. Chinese Karstology; Geological Publishing House: Beijing, China, 1993. (In Chinese)

18. Yang, M.D. Study the Vulnerability of Karst Environment; Nationality Publishing House: Guiyang, China, 1990. (In Chinese) 
19. Xie, X.N.; Wang S.J.; Zhou. Y.C. Three-dimensional fluorescence spectral characteristics of dissolved organic carbon in cave drip waters and their responses to environment changes: Four cave systems as an example in Guizhou Province, China. Chin. Sci. Bull. 2008, 53, 884-889.

20. Gilberto, G.C. Linkages between vulnerability, resilience, and adaptive capacity. Golb. Environ. Chang. 2006, 16, 293-303.

21. Shannon, C. The mathematical theory of communication. Bell Syst. Tech. J. 1948, 27, 379-423.

22. Deng, J.L. Control problems of grey systems. Syst. Control Lett. 1982, 1, 288-294.

23. Ng, D.K.W.; Deng, J. Contrasting grey system theory to probability and fuzzy. J. Grey Syst. 1995, 20,3-9.

24. Yi, L.N.; Liu, S.F. Solving Problems with Incomplete Information: A Grey Systems Approach. Adv. Imaging Electron. Phys. 2006, 141, 77-174.

25. Liu, S.F.; Li, Y. Grey Information: Theory and Practical Applications; Springer-Verlag: London, UK, 2005.

26. Hao, H. Gray correlation model of enterprise commercial credit risk assessment. Inf. Comput. Appl. 2013, 391, 519-530.

27. Luthar, S.S.; Cicchetti, D. The construct of resilience: Implications for interventions and social policies. Dev. Psychopathol. 2000, 12, 857-885.

28. Walker, B.; Holling, C.S.; Carpenter, S.R.; Kinzig, A. Resilience, adaptability and transformability in social-ecological systems. Ecol. Soc. 2004, 9, Article 5.

29. Zhang, B.P.; Xiao, F.; Wu, H.Z.; Mo, S.G.; Zhu, S.Q.; Yu, L.F.; Xiong, K.N.; Lan, A.J. Combating the Fragile Karst Environment in Guizhou, China. AMBIO 2006, 35, 94-97.

30. Ouyang, Z.Y.; Wang, X.K.; Miao, H. China's Eco-environmental sensitivity and its spatial heterogeneity. Acta Ecol. Sin. 2000, 20, 9-12. (In Chinese)

31. Ortega, S.T.; Hanley, N.; Simal, P.D. A Proposed Methodology for Prioritizing Project Effects to Include in Cost-Benefit Analysis Using Resilience, Vulnerability and Risk Perception. Sustainability 2014, 6, 7945-7966.

32. Zhang, D.F; Ouyang, Z.Y.; Wang, S.J. Population Resources Environment and Sustainable Development in the Karst Region of Southwest China. China Popul. Resour. Environ. 2011, 11, 77-81. (In Chinese)

(C) 2015 by the authors; licensee MDPI, Basel, Switzerland. This article is an open access article distributed under the terms and conditions of the Creative Commons Attribution license (http://creativecommons.org/licenses/by/4.0/). 